\title{
APROXIMAÇÃO COMPARATIVA SOBRE O PAPEL DO CIDADÃO EM DIFERENTES PARADIGMAS DE CIDADES
}

\section{COMPARATIVE APPROACH TO THE CITIZEN'S ROLE IN DIFFERENT CITY PARADIGMS}

\author{
Felipe Chibás Ortiz \\ Centro de Estudos de Avaliação e Mensuração em Comunicação e Marketing (CEACOM)da Universidade de \\ São Paulo (USP) \\ chibas f@yahoo.es
}

Grazielle Anjos Carvalho

CEO: Instituto Smart Citizen grazielleanjoo@gmail.com

Elivelton da Silva Fonseca

Instituto de Geografia, Universidade Federal de Uberlândia elivelton.fonseca@gmail.com

Samuel do Carmo Lima

Laboratório de Geografia Médica, Instituto de Geografia, Universidade Federal de Uberlândia samuel@ufu.br

\begin{abstract}
RESUMO
O presente trabalho tem por objetivo principal realizar uma aproximação comparativa de diferentes tipos de cidadãos constituídos em distintos framework ou paradigmas de cidade, implementados em distintos espaços urbanos. Para isso foi utilizada a metodologia teóricoprática e comparativa, que incluiu levantamento bibliográfico, virtual e sitiográfico. Foram reelaborados dois quadros descritivos e comparativos, que reúnem os principais dados de seis framework de cidades e seis tipos de cidadãos a eles correspondentes. Os paradigmas, frameworks de cidades mais citados e debatidos atualmente, que estabelecem sintonia com os 17 Objetivos do Desenvolvimento propostos pela ONU para 2031, são os mais pertinentes para o enfrentamento da atual situação de pandemia provocada pelo COVID-19. Nas considerações finais pondera-se a respeito de quando utilizar cada framework de cidade.
\end{abstract}

Palavras Chave: Cidades MIL. UNESCO. Quadro de Cidades. COVID-19. Cidadania.

\begin{abstract}
The present work has as main objective to carry out a comparative approach of different types of citizens constituted in different frameworks or paradigms of the city, implemented in different urban spaces. For that, the theoretical-practical and comparative methodology was used, which included bibliographic, virtual and sitiographic survey. Two descriptive and comparative tables were reworked which bring together the main data from 6 city frameworks and 6 types of citizens corresponding to them. The paradigms, frameworks of cities most cited and debated today, which are in line with the 17 Development Goals proposed by the UN for 2031, are the most pertinent to face the current pandemic situation caused by COVID-19. In the final considerations, we ponder on when to use each city framework.
\end{abstract}

Keywords: MIL cities. UNESCO. Cities Framework. COVID-19. Citizenship.

\section{INTRODUÇÃO}

Antes das famosas polis, na Grécia antiga, havia grandes cidades dotadas de uma organização urbana memorável, como a cidade-estado de Babilônia, na Ásia, há mais de 5.000 anos atrás, conhecida por seus palácios de vários andares, com árvores e jardins integrados (SILVA, 2020) e

Recebido em: 10/01/2021

Aceito para publicação em: 05/02/2021.

$\begin{array}{lllllll}\text { Hygeia } & \text { Uberlândia - MG } & \text { v. } 18 & 2022 & \text { p. 1-13 } & \text { Página } 1\end{array}$


Tebas, capital do Egito, nordeste da África, por mais de 1500 anos (1550 a.C. - 1070 a.C.). Esta última foi considerada a cidade mais sofisticada do mundo antigo. Originalmente nomeada "Uaset" (o cetro) foi também conhecida pelo nome "Niwt" (a cidade) no Egito (COSTA, 2020).

Ainda que posteriores às polis gregas, também podemos citar como exemplos de cidades de origem distinta da grega, as latino-americanas, antes da colonização de Tenochtitlan e Cuzco. A primeira delas, fundada em 1325, possuía aproximadamente 200 mil habitantes, um complexo ecossistema de prédios altos, canais e lagoas artificiais e, em 1519, quando os espanhóis chegaram à Meso-américa, era considerada a capital do Império Asteca (CHING et al, 2019). A cidade de Cuzco, a 3400 metros acima do nível do mar, hoje no atual Peru, era a capital do Tahuantinsuyu, ou Império Inca e tinha uma população em torno de 428.450 habitantes (FRAGA, 2017).

O comportamento dos cidadãos destas cidades era pautado por regras e normas sociais de convívio, tendo até mesmo um sistema de punições para aquele que não as seguissem, como o famoso Código de Hamurabi na antiga Pérsia ("Código de Hamurabi", 2020).

Desde o período arcaico até o período clássico o modelo das antigas cidades gregas tinha por fundamento $\mathrm{o}$ conceito de polis. Estas cidades, de forma semelhante às anteriormente mencionadas, eram cidades-Estado e adotavam modo de vida urbano.

Apesar de também nessas cidades haver pessoas escravizadas, nelas foi fomentada a práxis e a ideia de democracia e de cidadania, especialmente no pensamento de filósofos entre os quais Sócrates, Platão e Aristóteles.

Essas cidades eram formadas, basicamente, por uma Acrópole, uma Ágora, uma Khora e uma Ástey. A acrópole, situada na parte mais elevada da polis, abrigava templos dedicados aos deuses. Logo abaixo dela estava a Ágora, a praça principal, parte mais pública da comunidade, com o mercado e as assembleias do povo. A khora compreendia a parte agrícola, onde moravam os camponeses e era ali que eram cultivados os alimentos que supriam a ástey, "cidade" da polis, porção urbana, isolada por uma muralha destinada à proteção contra ataques de outras cidades (MALACO, 2018).

Entende-se por cidadania é a prática de direitos e deveres de um (a) indivíduo (pessoa) em um Estado e entende-se por cidadão o indivíduo praticante da cidadania (BARRETO, 1993). Etimologicamente, a palavra cidadania advém do latim civitas, cidade, tal como cidadão (ciudadano ou vecino em espanhol, ciutadan em provençal, citoyen em francês). Neste sentido, a palavra-raiz, cidade, diz muito sobre o verbete.

No cumprimento dos seus deveres o habitante da cidade é um sujeito de ação, em contraposição a um sujeito de contemplação, omisso e absorvido por si e para si mesmo. Ou seja, não basta estar na cidade: é preciso agir na cidade. Cidadania, neste contexto, refere-se à qualidade de cidadão, indivíduo de ação estabelecido na cidade moderna (ARENDT, 2016).

Todas essas questões acham-se intimamente relacionadas à Declaração Universal dos Direitos Humanos, adotada pela Assembleia Geral das Nações Unidas (Resolução 217 A III) de 10 de dezembro de 1948 (ONU). Este documento, elaborado por representantes de diferentes origens jurídicas e culturais de todas as regiões do mundo, proclama os direitos humanos e de cidadania, tais como o direito à moradia, à educação e à saúde, entre tantos outros (ONU, 1948).

A Declaração Universal dos Direitos Humanos foi inspirada pelo Cilindro de Ciro, que contém uma declaração do rei persa Ciro II, realizada após sua conquista da Babilônia em 539 a.C. O Cilindro de Ciro, descoberto em 1879, foi traduzido em 1971 para todos os idiomas oficiais da Organização das Nações Unidas. Nele, era declarado o direito à liberdade de religião e era defendida a abolição da escravatura, resultado de uma tradição mesopotâmica centrada na figura do "rei justo", cujo primeiro exemplo conhecido é o rei Urukagina, de Lagash, que reinou durante o século XXIV a.C. (KUHRT, 2009).

O objetivo principal deste artigo é realizar uma primeira aproximação comparativa aos diferentes tipos de cidadãos que podem se formar a partir do framework ou paradigma de cidade implementado em diferentes espaços urbanos. Na construção do argumento, pensa-se o inovador conceito de geo-letramento como relevante contribuição teórica. Para atingir nossos objetivos utilizamos a metodologia teórico-prática e comparativa, que inclui levantamento bibliográfico, virtual e sitiográfico.

\begin{tabular}{lllllll}
\hline Hygeia & Uberlândia - MG & v. 18 & 2022 & p. 1-13 & Página 2
\end{tabular}




\section{METODOLOGIA}

Para a realização deste trabalho foi utilizada a metodologia teórico-prática, de natureza essencialmente qualitativa e uma primeira análise exploratória comparativa com base na metodologia multicasos proposta por Robert Yin (2014), constituída na revisão bibliográfica e local. Para reunir dados relativos aos seis framework de cidades e seis tipos de cidadãos a eles correspondentes, foram elaborados dois quadros descritivos e comparativos, tomando por base quadros elaborados anteriormente por diversos autores.

Os critérios de seleção levaram em consideração os seguintes fatores: (1) trata-se de frameworks que respondem a paradigmas de cidades dos mais citados e debatidos atualmente; (2) eles estabelecem sintonia com os 17 Objetivos do Desenvolvimento Sustentável (ODS) propostos pela ONU para a Agenda 2030 (2020); (3) são os frameworks por nós considerados mais pertinentes para o enfrentamento de uma situação de pandemia (UNITED NATIONS, 2020).

O procedimento de pesquisa incluiu levantamento bibliográfico e virtual de dados sobre as cidades e rankings colocados em questão, durante o período compreendido entre janeiro e agosto de 2020; leitura crítica e revisão de documentos físicos e outros, veiculados on line - sites, blogs e redes sociais.

\section{RESULTADOS E DISCUSSÃO \\ SEIS DIFERENTES PARADIGMAS DE CIDADES ATUAIS}

Entre os paradigmas de cidades mais debatidos atualmente elegemos seis por considerarmos que serão estes os mais utilizados no enfrentamento da situação de pandemia e pós-pandemia provocada pelo COVID-19, doença que até 08 de janeiro de 2021 (WORLD HEALTH ORGANIZATION, 2021) já provocara um total de 86.436.449 casos confirmados e 1.884 .341 casos de morte. Os paradigmas de cidades eleitos por nós são os seguintes:
a. $\quad$ Cidades Saudáveis (1986);
b. $\quad$ Cidades Educadoras (1990);
c. Cidades Sustentáveis (1997);
d. Cidades Resilientes (2010);
e. $\quad$ Cidades Inteligentes (2010);
f. $\quad$ Cidades MIL (2018).

O Quadro 1, reúne dados relativos às principais características de cada um dos seis paradigmas e cidades. Tais dados foram organizados em colunas que reúnem, especificamente, dados sobre a função, os objetivos, os métodos e alguns exemplos de cada um desses paradigmas.

O conceito de Cidades Saudáveis foi inspirado pela Carta de Ottawa para a Promoção da Saúde, elaborada durante a I Conferência Internacional sobre Promoção da Saúde Ottawa, realizada em novembro de 1986 na cidade de Ottawa, Canadá, com a intenção de contribuir para a conquista de Saúde para Todos no Ano 2000 e anos subsequentes. Compreendida a saúde como algo criado e vivido pelas pessoas nas configurações de sua vida cotidiana, essa Carta de Intenções considera onde as pessoas aprendem, trabalham, se divertem e amam. Segundo a Organização Mundial de Saúde (2020), esse conceito ocupa o centro da abordagem de Configurações Saudáveis, que aprofunda raízes na estratégia Saúde para Todos, da OMS. (LIMA; LIMA, 2020).

Tendo por objetivo maximizar a prevenção de doenças por meio de uma abordagem de "sistema integral", cujas ações multidisciplinares incidem sobre fatores de risco e vulnerabilidades sociais, o programa Cidades Saudáveis é o exemplo mais conhecido de abordagem bem-sucedida de Configurações Saudáveis. Iniciadas pela OMS em 1986, as Cidades Saudáveis se expandiram rapidamente pela Europa e outras partes do mundo (LIMA; LIMA, 2020). 
Quadro 1 - Estudo comparativo de paradigmas contemporâneos de cidade

\begin{tabular}{|c|c|c|c|c|}
\hline $\begin{array}{c}\text { Paradigma de } \\
\text { Cidades } \\
\end{array}$ & Função & Missão//Objetivos & Métodos & Exemplos \\
\hline $\begin{array}{l}\text { Cidades Saudáveis } \\
\text {-1986 (OMS, 2020) }\end{array}$ & $\begin{array}{l}\text { Criar e melhorar } \\
\text { continuamente } \\
\text { ambientes físicos e } \\
\text { sociais, expandindo } \\
\text { os recursos da } \\
\text { comunidade que } \\
\text { permitem que as } \\
\text { pessoas se apoiem } \\
\text { mutuamente no } \\
\text { desempenho de } \\
\text { todas as funções da } \\
\text { vida e no } \\
\text { desenvolvimento } \\
\text { máximo de seu } \\
\text { potencial. }\end{array}$ & $\begin{array}{l}\text { - Maximizar a } \\
\text { prevenção de } \\
\text { doenças por meio de } \\
\text { uma abordagem de } \\
\text { "sistema inteiro", que } \\
\text { integra ações } \\
\text { multidisciplinares } \\
\text { entre os fatores de } \\
\text { risco. Criar um } \\
\text { ambiente favorável à } \\
\text { saúde para alcançar } \\
\text { uma boa qualidade } \\
\text { de vida, } \\
\text { - Fornecer condições } \\
\text { de satisfação das } \\
\text { necessidades básicas } \\
\text { de saneamento e } \\
\text { higiene e acesso aos } \\
\text { cuidados de saúde. } \\
\text { - Comprometer-se a } \\
\text { melhorar os } \\
\text { arredores de uma } \\
\text { cidade e dispor-se a } \\
\text { criar as necessárias } \\
\text { conexões entre as } \\
\text { arenas políticas, } \\
\text { econômicas e sociais. }\end{array}$ & \begin{tabular}{l||} 
- Investimento em \\
capital humano e \\
social como \\
abordagem \\
estratégica para o \\
desenvolvimento \\
urbano. \\
\\
\\
- Promoção da \\
inclusão, integração \\
e não discriminação \\
para promover \\
confiança, resiliência \\
e foco na ética e nos \\
valores.
\end{tabular} & $\begin{array}{l}\text { 1) Gold Coast, } \\
\text { Australia } \\
\text { 2) Amsterdam, } \\
\text { Holanda } \\
\\
\text { 3) Munique, } \\
\text { Alemanha }\end{array}$ \\
\hline $\begin{array}{l}\text { Cidades } \\
\text { Educadoras- } 1990 \\
\text { (Ministério da } \\
\text { Educação, 2011) }\end{array}$ & $\begin{array}{l}\text { Investir na vida } \\
\text { cultural e na } \\
\text { formação } \\
\text { permanente de sua } \\
\text { população. }\end{array}$ & $\begin{array}{l}\text { - Promover } \\
\text { educação, } \\
\text { diversidade, } \\
\text { compreensão, } \\
\text { cooperação e paz } \\
\text { internacional } \\
\text { - Evitar exclusão } \\
\text { motivada por } \\
\text { diversidade étnico- } \\
\text { racial, sexo, cultura, } \\
\text { idade, deficiência, } \\
\text { condição econômica } \\
\text { e outros tipos de } \\
\text { discriminação. } \\
\text { - Estabelecer } \\
\text { colaboração bilateral } \\
\text { ou multilateral entre } \\
\text { cidades para a troca } \\
\text { de experiências. } \\
\text { - Propor políticas de } \\
\text { Educação voltadas } \\
\text { para a infância. }\end{array}$ & \begin{tabular}{|l||} 
\\
\\
- Formação, \\
promoção e \\
desenvolvimento de \\
todos os seus \\
habitantes, a \\
começar pelas \\
crianças e jovens. \\
- Adotar a \\
intersetorialidade \\
como premissa \\
norteadora das \\
ações e como \\
recurso estratégico \\
de articulação entre \\
instituições, pessoas \\
e saberes.
\end{tabular} & $\begin{array}{l}\text { 1) Barcelona, } \\
\text { Espanha } \\
\text { 2) Bolonha, } \\
\text { Itália } \\
\text { 3) Belo Horizonte, } \\
\text { Brasil }\end{array}$ \\
\hline
\end{tabular}




\begin{tabular}{|c|c|c|c|c|}
\hline $\begin{array}{l}\text { Cidades } \\
\text { Resilientes-2010 } \\
\text { (100 Resilient Cities, } \\
\text { 2019) }\end{array}$ & $\begin{array}{l}\text { Novos modelos de } \\
\text { governança para } \\
\text { mitigar riscos e } \\
\text { responder aos } \\
\text { desafios. }\end{array}$ & \begin{tabular}{|l} 
- Contornar o \\
problema das \\
filosofias cívicas e \\
culturais conflitantes, \\
concentrando-se na \\
solução de problemas \\
específicos. \\
- Estabelecer uma \\
estrutura \\
organizacional e \\
identificar os \\
processos \\
necessários para \\
compreender e agir. \\
- Reduzir a \\
exposição, o impacto \\
e a vulnerabilidade a \\
desastres. \\
\end{tabular} & \begin{tabular}{||l} 
\\
- Capacidade de \\
uma cidade de \\
perseverar apesar \\
dos desafios. \\
- Tem como \\
propósito central sua \\
responsabilidade \\
para com seus \\
cidadãos.
\end{tabular} & $\begin{array}{l}\text { 1) Accra, } \\
\text { Ghana } \\
\text { 2) Veneza } \\
\text { Itália } \\
\\
\text { 3) Lagos } \\
\text { Nigéria }\end{array}$ \\
\hline $\begin{array}{l}\text { Cidades } \\
\text { Sustentáveis } \\
-1997 \\
\text { (Guevara, Maulen, } \\
\text { Marinho, Eterovic, } \\
2019)\end{array}$ & $\begin{array}{l}\text { O tipo mais durável } \\
\text { de assentamento } \\
\text { que o ser humano é } \\
\text { capaz de construir. }\end{array}$ & \begin{tabular}{||l} 
- Utilizar nova lógica \\
de funcionamento, \\
gestão e crescimento, \\
em detrimento das \\
anteriormente \\
praticadas, \\
principalmente no \\
século XX. \\
\\
- Fundamentar-se na \\
ideia de "expansão \\
com esgotamento".
\end{tabular} & $\begin{array}{l}\text { - Cidade capaz de } \\
\text { propiciar um padrão } \\
\text { de vida aceitável } \\
\text { sem causar sérios } \\
\text { prejuízos ao } \\
\text { ecossistema ou aos } \\
\text { ciclos } \\
\text { biogeoquímicos dos } \\
\text { quais depende. } \\
\text { Trata-se de um } \\
\text { processo de longo } \\
\text { prazo } \\
\text { que requer esforços } \\
\text { também da } \\
\text { população. }\end{array}$ & \begin{tabular}{|l} 
1) Freiburg \\
Germany \\
2) Malmö \\
Suécia. \\
3) Vancouver \\
Canadá
\end{tabular} \\
\hline $\begin{array}{l}\text { Cidades } \\
\text { Inteligentes-2010 } \\
\text { (Fundação Getulio } \\
\text { Vargas, 2019) }\end{array}$ & $\begin{array}{l}\text { Uso de tecnologia } \\
\text { no planejamento } \\
\text { urbano e } \\
\text { participação civil. }\end{array}$ & \begin{tabular}{|l} 
- Ser sustentável. \\
- Oferecer qualidade \\
de vida. \\
- Usar sistemas \\
inteligentes para \\
catalisar o \\
desenvolvimento \\
econômico.
\end{tabular} & \begin{tabular}{||l} 
- Governança, \\
administração \\
pública, \\
planejamento \\
urbano, tecnologia, \\
conexões \\
internacionais, \\
coesão social, \\
capital humano e \\
economia. \\
\end{tabular} & $\begin{array}{l}\text { 1) Songdo } \\
\text { Coreia do Sul } \\
\text { 2) Copenhague } \\
\text { Dinamarca } \\
\\
\text { 3) Santa Ana } \\
\text { Estados Unidos }\end{array}$ \\
\hline $\begin{array}{l}\text { Cidades MIL (Media } \\
\text { and Information } \\
\text { Literacy) } \\
\text { ou com } \\
\text { Alfabetização } \\
\text { Midiática e } \\
\text { Informacional 2018 } \\
\text { (UNESCO, 2020a) }\end{array}$ & $\begin{array}{l}\text { Acesso igualitário à } \\
\text { informação e ao } \\
\text { conhecimento, bem } \\
\text { como sistemas de } \\
\text { mídia e informação } \\
\text { livres, } \\
\text { independentes e } \\
\text { plurais. }\end{array}$ & $\begin{array}{l}\text { - Empoderar } \\
\text { cidadãos fornecendo- } \\
\text { Ihes competências } \\
\text { (conhecimento, } \\
\text { habilidades e } \\
\text { atitudes) necessárias } \\
\text { à implementação de } \\
\text { mídia tradicional e } \\
\text { novas tecnologias, } \\
\text { por utilizar todas as } \\
\text { formas de mídia e de } \\
\text { provedores de } \\
\text { informação } \\
\text { (bibliotecas, arquivos, } \\
\text { museus, internet etc. }\end{array}$ & $\begin{array}{l}\text { Centra-se em } \\
\text { competências } \\
\text { diferentes e } \\
\text { interligadas para } \\
\text { transformar a } \\
\text { interação das } \\
\text { pessoas com } \\
\text { informações e } \\
\text { ambientes de } \\
\text { aprendizagem online } \\
\text { e offline. }\end{array}$ & $\begin{array}{l}\text { 1) Belford } \\
\text { Inglaterra } \\
\text { 2) Helsinki } \\
\text { Finlândia } \\
\text { 3) Glasgow } \\
\text { Escócia }\end{array}$ \\
\hline
\end{tabular}

Fonte: Adaptado de CHIBÁS ORTIZ, GRIZZLE, BORGES, RAMOS, MAZZETTI, SILVA JUNIOR, 2020.

\begin{tabular}{lllllll}
\hline Hygeia & Uberlândia - MG & v. 18 & 2022 & p. 1-13 & Página & 5
\end{tabular}


Uma cidade saudável não depende da infraestrutura de saúde vigente, mas sim do compromisso de melhorar os arredores de uma cidade e da disposição para criar as necessárias conexões entre as arenas políticas, econômicas e sociais. Exemplos de Cidades Saudáveis são Gold Coast, na Austrália; Amsterdã, na Holanda e Munique, na Alemanha.

O conceito de Cidades Educadoras, por sua vez, surgido nos anos 1990, trouxe, em essência, como ideia central, a de investimento cultural e formação permanente de sua população. Tendo por objetivos promover educação, apreço à diversidade, à compreensão, à cooperação e à paz internacional e, simultaneamente, evitar exclusões motivadas por diversidade de raça e etnia, de sexo e gênero, de cultura, de idade, de deficiências, de condição econômica e de outras modalidades de discriminação. Segundo o Ministério da Educação e Cultura do Brasil (2011), as Cidades Educadoras têm por objetivos promover a formação e o desenvolvimento de todos os seus habitantes, a começar por crianças e jovens e garantir a intersetorialidade como premissa norteadora das ações e da escolha de recursos estratégicos de articulação entre pessoas, instituições e saberes.

Segundo a Carta das Cidades Educadoras, criada e disponibilizada pela Asociación Internacional de Ciudades Educadoras (2019), pretende-se que as Cidades Educadoras estabeleçam entre si colaboração bilateral ou multilateral para a troca de experiências e adotem políticas educacionais voltadas para a infância. Cidades como Barcelona, na Espanha; Bolonha, na Itália e Belo Horizonte, no Brasil, são exemplos de Cidades Educadoras (EDCITIES, 1990).

O conceito de Cidades Resilientes, estabelecido em 2010 por meio da ONU, destaca novos modelos de governança pública voltados para mitigar riscos e responder a desafios específicos de cada localidade. Segundo o Jornal The Guardian (2014), na reportagem "What makes a city resilient?", a intenção é contornar o problema das filosofias cívicas e culturais conflitantes e concentrar-se na busca de solução para problemas específicos, privilegiando, em cada cidade, a capacidade de perseverar apesar dos desafios e de utilizar uma metodologia de solução de problemas que tenha a responsabilidade para com seus cidadãos como propósito central (WATSON, 2020).

Segundo a organização 100 Resilient Cities (2019), as Cidades Resilientes se caracterizam por estabelecer uma estrutura organizacional e identificar quais processos são necessários para compreender e agir em prol da redução de sua exposição, de impactos e de vulnerabilidade a desastres. São exemplos de Cidades Resilientes Accra, em Ghana; Veneza, na Itália e Lagos, na Nigéria (WATSON, 2020).

O modelo e a dinâmica de desenvolvimento das Cidades Sustentáveis, projetadas levando em consideração os impactos socioambientais, enfatizam a importância dos padrões de consumo e do respeito pelos recursos naturais, uma vez que visam a preservá-los para as gerações futuras. Servindo-se do poder de influência das compras públicas sobre os fornecedores, estas cidades podem adotar critérios de compra exclusiva de produtos avaliados como sustentáveis. Com experiência na implantação de gestão ambiental na administração municipal, as compras públicas sustentáveis, a eficiência energética e a gestão em edifícios públicos são temas recorrentes neste modelo de cidade (BATTEN, 2018).

Cidades Sustentáveis são, pois, o tipo mais durável de assentamento que o ser humano é capaz de construir. Diante da ideia de "expansão com esgotamento", propõem uma lógica alternativa de funcionamento, gestão e crescimento que se opõe à lógica adotada anteriormente, principalmente no século XX. Trata-se de um paradigma de cidade capaz de propiciar um padrão de vida aceitável sem causar profundos prejuízos ao ecossistema ou aos ciclos biogeoquímicos de que esse padrão depende. É um processo de longo prazo que requer esforço também da população (MAULEN, I.; MARINHO, C.; ETEROVIC, R., 2019).

O ranking de Cidades Sustentáveis elaborado em 2018 pela empresa americana de consultoria Arcadis considerou três fatores ao avaliar os centros urbanos ao redor do mundo: Pessoas, Lucro e Planeta. O levantamento teve por objetivo explicar as implicações da experiência de um cidadão, destacando diversas necessidades emergentes, como a conectividade digital e descreveu como tais necessidades vêm sendo atendidas em cidades de todos os níveis de sustentabilidade. Esse ranking possibilita maior compreensão das características subjacentes das cidades que permitem que algumas delas superem seus pares (BATTEN, 2018).

Para melhor compreensão da importância dos três pilares de avaliação, tomemos como exemplo o pilar Lucro, impulsionador de uma sustentabilidade de longo prazo, que demonstra a necessidade que as cidades de classificação média têm de melhorar seu desempenho nos três pilares, como

\begin{tabular}{lllllll}
\hline Hygeia & Uberlândia - MG & v. 18 & 2022 & p. 1-13 & Página 6
\end{tabular}


elemento diferenciador. Demonstra, também, o potencial crescente das cidades de utilizarem a evolução digital de sua prestação de serviços para promover seu engajamento com os cidadãos e para melhorar a experiência do cidadão na vida da cidade.

É interessante notar que embora as 20 principais cidades sustentáveis sejam, em sua maioria, metrópoles europeias estabelecidas, o ranking das 5 primeiras cidades são, respectivamente, os seguintes: 1) Londres, 2) Estocolmo, 3) Edimburgo, 4) Cingapura e 5) Viena.

O conceito de Cidades Inteligentes (Smart Cities) também surgiu em 2010, ao oferecer um modelo de cidade altamente funcional, baseada no uso de tecnologia no planejamento urbano e de participação civil para ser sustentável e oferecer qualidade de vida a seus habitantes. Segundo a Fundação Getúlio Vargas (2019), seus métodos se baseiam em governança, administração pública, planejamento urbano, elevado investimento em tecnologia, meio-ambiente, conexões internacionais, coesão social, capital humano e economia.

No artigo intitulado "Cidades inteligentes e sustentáveis: estudo bibliométrico e de informações patentárias", presente no periódico International Journal of Innovation: IJI Journal (2017), fica clara a visão dessas cidades que utilizam sistemas inteligentes para catalisar o desenvolvimento econômico, a exemplo de cidades como Songdo, na Coreia do Sul; Copenhague, na Dinamarca e Santa Ana, nos Estados Unidos (MOUTON et al., 2019).

Por fim, as Cidades MIL, baseadas em forte conceito de Alfabetização Midiática e Informacional (Media and Information Literacy - MIL), surgiram mais recentemente, em 2018, durante a Conferência Global MIL, promovida pela UNESCO e realizada na Lituânia naquele mesmo ano (GRIZZLE, 2020). Tendo por foco a utilização ética das tecnologias nas cidades, visa a empoderar cidadãos, fornecendo-Ihes as competências (conhecimento, habilidades e atitudes) necessárias para associar a mídia tradicional com as novas tecnologias.

A principal ferramenta para a formação de pensamento crítico na cidade é a educação. Segundo a UNESCO (2020), essa formação deve estar centrada em distintas competências interligadas para transformar a interação das pessoas por meio de informações e ambientes de aprendizagem online e offline e assim promover acesso igualitário à informação e ao conhecimento, o que supõe a constituição de sistemas de mídia e informação livres, independentes e plurais (UNESCO, 2020b).

Assim, as Cidades MIL (ou AMI) consideram todas as formas de mídia e outros provedores de informação como bibliotecas, arquivos, museus e internet, independentemente da tecnologia utilizada (UNESCO, 2020a). Cidades como Belford, na Inglaterra; Helsinki, na Finlândia e Glasgow, na Escócia são citadas como exemplos de Cidades MIL. Este paradigma coloca entre seus principais desafios transcender ou eludir as barreiras culturais na comunicação, enfrentadas, por exemplo, por pessoas que saem do padrão promovido pelo discurso historicamente hegemônico por serem emigrantes, mulheres, LGBTQ+, negros, vítimas de intolerância religiosa, idosos e jovens entre outros. Recentemente (2020) foi criada a Rede de Cidades MIL, integrando, entre outras, as cidades de Kingston, na Jamaica; Puebla, no México e 15 cidades do Paraguai, entre as quais Assunção, sua capital.

Trata-se de construir cidades não apenas com argamassa e tecnologia, mas, também, com informações que possibilitem às pessoas a aquisição de indispensáveis competências de mídia e informação para obtenção máxima dos benefícios da informação: eis aqui um dos relevantes focos das Cidades MIL. Muitas teorias e conceitos podem ser aplicados às Cidades MIL devido à sua natureza interdisciplinar. Assim, coletivamente, o enfoque MIL nasce da associação de estudos de mídia e comunicação; de informação e biblioteca; de tecnologias próprias das sociedades da informação e do conhecimento.

Isto abre novas oportunidades propiciadoras de inspiração para a inovação empresarial na área de informação, tecnologia digital e mídia, inovação essa que combina atividades nos espaços físicos da cidade com aquelas dos espaços virtuais da cidade.

Tendo por foco as cidades como espaços de aprendizagem, interação social e diálogo, muitos especialistas propuseram Cidades como salas de aula - levando o aprendizado para fora dos espaços tradicionais de ensino em sala de aula (GRIZZLE, 2021). Isto implica em novas oportunidades para empresas e empreendedores promoverem as Cidades MIL. Por exemplo, as empresas de transporte público e privado, a indústria do entretenimento e a indústria da publicidade, principais distribuidores de informações nas cidades, desempenham papel fundamental na formação das Cidades MIL.

\begin{tabular}{lllllll}
\hline Hygeia & Uberlândia - MG & v. 18 & 2022 & p. 1-13 & Página 7
\end{tabular}


Atualmente há solicitações de outras cidades do mundo, o que demonstra a ampliação do interesse pelo tema. Também na Declaração de Seul, fruto do MIL Week 2020, é destacada a importância de fortalecer essa Rede (UNESCO, 2020b).

Ao realizarmos uma análise geral dos seis tipos de Cidades elencados e descritos anteriormente, mostra-se notável a semelhança de alguns paradigmas entre si, seja em contexto de sua criação, seja relativamente a seus objetivos, métodos de ação e aplicação ou mesmo sua visão.

Isto torna possível identificar quatro nichos principais de cidades e seus respectivos valores e focos de ação: destaca-se o teor econômico em Cidades como as Resilientes e Inteligentes; o teor tecnológico em Cidades Inteligentes e MIL; o teor socioambiental em Cidades Resilientes e MIL, o teor saúde em cidades Saudáveis e MIL e, por fim, o teor cultural e educacional em Cidades Educadoras e MIL (UNESCO, 2020b).

Disto se conclui que todos os conceitos de Cidades se aproximam quanto a determinadas características e se diferem quanto a outras. Mas é justamente a constante interdisciplinaridade destes conceitos e o permanente diálogo mantido entre teoria e prática que garantem a atualização de debates acerca de urbanismo, meio ambiente, tecnologia, economia, educação e cultura nas Cidades do futuro.

\section{PAPEL DO CIDADÃO EM CADA PARADIGMA DE CIDADE}

O Quadro 2, reúne dados relativos à relação entre Paradigmas de Cidade e Cidadãos habitantes dessas Cidades: seus valores predominantes; suas competências e seu perfil comportamental.

Cada um dos modelos descritos resumidamente no Quadro 2 incita ou influencia o surgimento de determinado tipo de cidadão. $E$ isto, é claro, não ocorre mecanicamente nem automaticamente: são tendências gerais.

Assim, por exemplo, espaços urbanos que aplicam o paradigma Cidades Saudáveis apresentam demandas para ações de intersetorialidade que tendem a provocar o surgimento de determinado perfil de cidadãos mais preocupados com a própria saúde e com a saúde coletiva e que percebem o fato de a saúde estar interconectada com outras dimensões da cidade, como a arborização e a segurança entre outras (LIMA; LIMA, 2020).

Nos espaços urbanos que aplicam o paradigma das Cidades Educadoras, o cidadão tende a desejar e usufruir das possibilidades educativas oferecidas pela cidade e, simultaneamente, busca contribuir com a educação dessa cidade. Sabe que tem direito de acesso a uma boa educação (EDCITIES, 1990). Esses indivíduos tendem a reconhecer que a educação é parte importante de seus direitos e deveres e que é este um dos fatores que mais contribuem para a formação de uma sociedade democrática. Quase sempre têm propósitos a esse respeito.

Nos espaços urbanos que adotam o modelo das Cidades Resilientes muitos cidadãos desejam contribuir ativamente para a reconstrução de sua cidade ou para a saída de uma situação de crises naturais ou provocadas pelo homem (WATSON, 2020). Essa atitude está presente, por exemplo, entre os habitantes de Hiroshima e Nagasaki, cidades japonesas atingidas por bombardeio nuclear.

Espaços urbanos que adotam o modelo das Cidades Sustentáveis têm por norma facilitar a manifestação de cidadãos preocupados com os impactos que a indústria, a tecnologia, as inovações e a ação humana em geral podem exercer sobre a natureza e a sociedade. É considerado que as mudanças podem ser administradas de maneira estratégica (a médio e longo prazo) para não produzirem impactos negativos (MAULEN; MARINHO; ETEROVIC, 2019). Os cidadãos buscam influenciar as autoridades para que não sejam implementados projetos e programas prejudiciais à natureza e à sociedade e que sejam sustentáveis. Esses indivíduos tendem a considerar que a preocupação com a natureza é parte relevante de seus direitos e deveres e têm fortes propósitos individuais e coletivos a serem colocados em prática em longo prazo. 
Quadro 2 - Relação entre Paradigmas de Cidade e Cidadãos dessas Cidades: seus valores predominantes; suas competências e seu perfil comportamental

\begin{tabular}{|c|c|c|c|}
\hline \multirow[b]{2}{*}{$\begin{array}{l}\text { Paradigma de } \\
\text { Cidade }\end{array}$} & \multicolumn{3}{|c|}{ Cidadãos } \\
\hline & Valores predominantes & $\begin{array}{l}\text { Competências } \\
\text { desenvolvidas }\end{array}$ & $\begin{array}{c}\text { Perfil } \\
\text { comportamental }\end{array}$ \\
\hline $\begin{array}{c}\text { Cidades } \\
\text { Saudáveis-1986 } \\
\text { (OMS, 2020; WHO, } \\
\text { 2020; WHO, 2021) }\end{array}$ & $\begin{array}{l}\text { - Saúde como bem estar } \\
\text { - Saúde bio-psico-social } \\
\text { - Saúde integral da cidade } \\
\text { - Saúde preventiva } \\
\text { - Multidisciplinaridade } \\
\text { - Humanismo } \\
\text { - Visão estratégica } \\
\text { - Sustentabilidade } \\
\text { - Educação }\end{array}$ & $\begin{array}{l}\text { - Observação da própria } \\
\text { saúde bio-psico-social } \\
\text { - Observação da própria } \\
\text { saúde bio-psico-social } \\
\text { em grupos específicos } \\
\text { - Observação de } \\
\text { indicadores e de } \\
\text { métricas da saúde na } \\
\text { cidade }\end{array}$ & $\begin{array}{l}\text { O cidadão se } \\
\text { preocupa com a } \\
\text { própria saúde e com } \\
\text { a saúde da } \\
\text { sociedade. } \\
\text { Percebe que a } \\
\text { saúde se } \\
\text { interconecta com } \\
\text { outras dimensões da } \\
\text { cidade - arborização, } \\
\text { segurança etc. }\end{array}$ \\
\hline $\begin{array}{c}\text { Cidades } \\
\text { Educadoras- 1990 } \\
\text { (Ministério da } \\
\text { Educação; 2011; } \\
\text { Asociación } \\
\text { Internacional de } \\
\text { Ciudades } \\
\text { Educadoras. 2018) }\end{array}$ & $\begin{array}{l}\text { - Educação e aprendizagem durante } \\
\text { toda a vida } \\
\text { - Conhecimento } \\
\text { - Multidisciplinariedade } \\
\text { - Cultura e arte } \\
\text { - Humanismo }\end{array}$ & $\begin{array}{l}\text { - Auto-aprendizagem } \\
\text { contínua } \\
\text { - Competências } \\
\text { didáticas } \\
\text { - Criatividade } \\
\text { - Flexibilidade } \\
\text { - Pensamento lógico e } \\
\text { abstrato } \\
\text { - Competências } \\
\text { multidisciplinares } \\
\text { - Conhecimento de } \\
\text { Filosofia } \\
\text { - Inteligência Emocional }\end{array}$ & $\begin{array}{l}\text { O cidadão deseja } \\
\text { usufruir } \\
\text { pessoalmente das } \\
\text { possibilidades } \\
\text { educativas } \\
\text { oferecidas pela } \\
\text { cidade e deseja } \\
\text { contribuir com a } \\
\text { educação dessa } \\
\text { cidade. }\end{array}$ \\
\hline $\begin{array}{c}\text { Cidades } \\
\text { Resilientes-2010 (; } \\
\text { The Guardian, } \\
\text { 2014; } 100 \text { Resilient } \\
\text { Cities, 2019) }\end{array}$ & $\begin{array}{l}\text { - Superação de adversidades, } \\
\text { conflitos e crises } \\
\text { - Valorização do planeta } \\
\text { - Visão estratégica } \\
\text { - Sustentabilidade }\end{array}$ & $\begin{array}{l}\text { - Resistência às } \\
\text { adversidades } \\
\text { - Flexibilidade } \\
\text { - Espírito de equipe } \\
\text { - Empatia } \\
\text { - Análise estratégica }\end{array}$ & $\begin{array}{l}\text { O cidadão deseja } \\
\text { contribuir ativamente } \\
\text { com a reconstrução } \\
\text { de sua cidade ou } \\
\text { com a saída de uma } \\
\text { situação de crise } \\
\text { enfrentada por ela. }\end{array}$ \\
\hline $\begin{array}{l}\text { Cidades } \\
\text { Sustentáveis- } \\
\text { 1997(Guevara, } \\
\text { Maulen, Marinho, } \\
\text { Eterovic, 2019) }\end{array}$ & $\begin{array}{l}\text { - Valorização do planeta } \\
\text { - Visão estratégica } \\
\text { - Sustentabilidade } \\
\text { - Multidisciplinaridade } \\
\text { - Consumo consciente }\end{array}$ & $\begin{array}{l}\text { - Humanismo } \\
\text { - Apreço à natureza - } \\
\text { Capacidade de análise } \\
\text { estratégica } \\
\text { - Conhecimento de } \\
\text { Economia e de } \\
\text { Economia Criativa e } \\
\text { Colaborativa }\end{array}$ & $\begin{array}{l}\text { O cidadão analisa se } \\
\text { as mudanças podem } \\
\text { ser mantidas de } \\
\text { maneira estratégica } \\
\text { (a médio e longo } \\
\text { prazo) sem provocar } \\
\text { impactos negativos } \\
\text { e tenta influenciar as } \\
\text { autoridades para } \\
\text { que não sejam } \\
\text { implementados } \\
\text { projetos e } \\
\text { programas } \\
\text { prejudiciais à } \\
\text { natureza e à } \\
\text { sociedade e outros } \\
\text { que não sejam } \\
\text { sustentáveis. }\end{array}$ \\
\hline $\begin{array}{c}\text { Cidades } \\
\text { Inteligentes- } \\
\text { 2010(KOREA } \\
\text { Planning. } \\
\text { 2017;Fundação } \\
\text { Getulio Vargas, } \\
\text { 2019.) }\end{array}$ & $\begin{array}{l}\text { - Novas tecnologias } \\
\text { - Inovação } \\
\text { - Gestão eficiente } \\
\text { - Novas tecnologias } \\
\text { - Inovação } \\
\text { - Agilidade } \\
\text { - Redução de custos } \\
\text { - Visão Estratégica } \\
\text { - Empreendedorismo }\end{array}$ & $\begin{array}{l}\text { - Habilidade para lidar } \\
\text { com tecnologia e com } \\
\text { dados } \\
\text { - Pensamento lógico } \\
\text { - Competência para a } \\
\text { Gestão de projetos e } \\
\text { para a Gestão } \\
\text { empreendedora } \\
\text { - Pensamento por } \\
\text { imagens } \\
\end{array}$ & $\begin{array}{l}\text { O cidadão defende } \\
\text { seu direito de } \\
\text { usufruir das novas } \\
\text { tecnologias para ter } \\
\text { mais autonomia, } \\
\text { mais tempo livre e } \\
\text { maior conforto }\end{array}$ \\
\hline
\end{tabular}




\begin{tabular}{|c|c|c|c|}
\hline & & $\begin{array}{l}\text { - Criatividade e } \\
\text { Inovação } \\
\text { - Habilidade para } \\
\text { trabalhar em ambientes } \\
\text { virtuais e blended } \\
\text { - Habilidade para lidar } \\
\text { com games } \\
\text { - Auto-aprendizagem } \\
\text { contínua } \\
\text { - Tele-trabalho }\end{array}$ & \\
\hline $\begin{array}{c}\text { Cidades MIL } \\
\text { (Media and } \\
\text { Information } \\
\text { Literacy) } \\
\text { ou } \\
\text { Cidades AMI } \\
\text { (Alfabetização } \\
\text { Midiática e } \\
\text { Informacional)- } \\
2018 \text { (GRIZZLE, } \\
2020 ; \text { UNESCO, } \\
\text { 2020a; UNESCO, } \\
\text { UNESCO, 2020b } \\
\text { 2020c) }\end{array}$ & $\begin{array}{l}\text { - Comunicação (Alfabetização } \\
\text { mediática e funcional) } \\
\text { - Visão crítica } \\
\text { - Visão Estratégica } \\
\text { - Visão Sistêmica } \\
\text { - Tecnologias } \\
\text { - Criatividade } \\
\text { - Inovação } \\
\text { - Ética } \\
\text { - Compartilhamento } \\
\text { - Parceria e gestão participativa e } \\
\text { democrática } \\
\text { - Multiculturalidade } \\
\text { - Multidisciplinaridade } \\
\text { - Evolução Contínua } \\
\text { - Transparência } \\
\text { - Diversidade } \\
\text { - Equidade } \\
\text { - Universalidade } \\
\text { - Sustentabilidade } \\
\text { - Pós Humanismo } \\
\text { - Cultura e Arte } \\
\text { - Geo-literacy (Geo-letramento) }\end{array}$ & $\begin{array}{l}\text { - Pensamento crítico } \\
\text { - Pensamento lógico } \\
\text { - Pensamento por } \\
\text { imagens (leitura de } \\
\text { infográficos) } \\
\text { - Criatividade } \\
\text { - Auto-aprendizagem } \\
\text { contínua } \\
\text { - Combate ao } \\
\text { analfabetismo funcional } \\
\text { - Inovação e Inovação } \\
\text { social } \\
\text { - Flexibilidade } \\
\text { 7- Reconhecer e } \\
\text { combater fake news } \\
\text { - Lidar com pós } \\
\text { verdades } \\
\text { - Trabalho colaborativo } \\
\text { - Comunicação } \\
\text { multicultural } \\
\text { - Resolução de conflitos } \\
\text { - Tolerância } \\
\text { - Valorização da } \\
\text { natureza } \\
\text { - Análise estratégica } \\
\text { - Empatia } \\
\text { - Habilidade para utilizar } \\
\text { a tecnologia e para lidar } \\
\text { com dados } \\
\text { - Habilidade para gerir } \\
\text { plataformas digitais e } \\
\text { outros meios de } \\
\text { comunicação } \\
\text { tradicionais (rádio, TV, } \\
\text { jornais impressos etc.) } \\
\text { - Habilidade para } \\
\text { trabalhar em ambientes } \\
\text { virtuais e blended } \\
\text { - Habilidade para lidar } \\
\text { com games } \\
\text { - Habilidade para lidar } \\
\text { com arte } \\
\text { - Habilidade para ler } \\
\text { mapas digitais e físicos, } \\
\text { bem como ler o espaço } \\
\text { físico } \\
\text { - Habilidade para se } \\
\text { localizar e se } \\
\text { movimentar nas cidades } \\
\text { de modo eficiente }\end{array}$ & $\begin{array}{l}\text { O cidadão defende } \\
\text { seu direito a usufruir } \\
\text { das novas } \\
\text { tecnologias, das } \\
\text { inovações e de } \\
\text { todos os recursos da } \\
\text { cidade de maneira } \\
\text { ética, diversa e } \\
\text { sustentável. } \\
\text { Preocupa-se com } \\
\text { que estes recursos } \\
\text { estejam em função } \\
\text { de resolver } \\
\text { problemas e } \\
\text { desafios enfrentados } \\
\text { por todos, aí } \\
\text { incluídas as } \\
\text { barreiras culturais } \\
\text { enfrentadas pelas } \\
\text { minorias - } \\
\text { imigrantes, grupos } \\
\text { vulneráveis, grupos } \\
\text { religiosos, étnicos, } \\
\text { de gênero, de } \\
\text { emigrantes etc. } \\
\text { Também se } \\
\text { preocupa com a } \\
\text { utilização de seus } \\
\text { dados, exigindo } \\
\text { transparência no uso } \\
\text { de informações, } \\
\text { identificando fake } \\
\text { news, deep fakes, } \\
\text { pós-verdades etc. }\end{array}$ \\
\hline
\end{tabular}

Fonte: Adaptado de CHIBÁS ORTIZ, 2021.

\begin{tabular}{lllllll}
\hline Hygeia & Uberlândia - MG & v. 18 & 2022 & p. 1-13 & Página & 10
\end{tabular}


Espaços urbanos que aplicam o paradigma Cidades Inteligentes tendem a formar cidadãos que defendem seu direito a usufruir das novas tecnologias para conquistarem mais autonomia, mais tempo livre e maior conforto, assim como diminuir os custos de suas operações (KOBAYASHI et al, 2017). Essas pessoas também se preocupam muito com a transparência das operações financeiras e as estratégias da tomada de decisões por parte das empresas privadas e das instituições públicas.

Espaços urbanos que aplicam o paradigma Cidades MIL tendem a formar cidadãos que defendem seu direito a usufruir das novas tecnologias, das inovações e de todos os recursos da cidade, de maneira ética, diversa e sustentável. Simultaneamente, há nessas cidades a preocupação de que os cidadãos estejam em função de resolver problemas e enfrentar desafios impostos a todos, aí incluídas as barreiras culturais enfrentadas pelas minorias - imigrantes, grupos vulneráveis, grupos religiosos, étnico-raciais, de gênero e emigrantes entre outros. Preocupam-se com a utilização de seus dados, com a transparência no uso da informação, com as fake news, as deep fakes, as pósverdades etc. Geralmente, os cidadãos dessas cidades têm pensamento crítico desenvolvido, se preocupam com os direitos e deveres de todos, inclusive das minorias e com a democracia, tendo fortes propósitos a este respeito (UNESCO, 2020b)

Como pode ser observado, cada um destes frameworks tende a influencias de uma forma específica as pessoas e a formar tipos específicos de cidadãos, havendo, no entanto, características comuns a todos os modelos de cidadão, tais como a tendência a formar pessoas preocupadas com os demais, que reconhecem ser a educação relevante fator de mudança dos espaços urbanos e que são dotadas de visão estratégica, abrangente e de longo prazo ao considerarem a própria cidade.

É certo que o cidadão comum, não conhece esses modelos, mas ele recebe as influências e é modificado por elas, mesmo sem ele saber esses "tipos ' de cidade e cidadãos. É inegável por exemplo, que se a cidade modifica-se em função de um paradigma de cidade sustentável, irão se fazer mais construções sustentáveis, vai se cuidar mais da natureza e se fará mais propaganda pela prefeitura sobre a importância da sustentabilidade da natureza e isso estará presente nos canais e veículos de comunicação físicos e digitais. Isto vai impactar aos cidadãos e modificar seus valores e comportamento, mesmo que eles não saibam o nome do processo e o tipo de cidadão no qual estão participando e transformando-os. De igual maneira acontece com os outros paradigmas.

\section{CONSIDERAÇÕES FINAIS}

É muito importante refletir a respeito do paradigma de cidade que se adota. O projeto de cidade adotado, consciente ou inconscientemente exercerá influência sobre o futuro da cidade e o tipo de cidadão nela fomentado.

É, pois, assunto peremptório a formação de verdadeiros cidadãos, capazes de utilizar as novas tecnologias, de opinar e de contribuir ativamente para modificar suas cidades para melhor, contribuindo, assim, para a promoção de uma gestão participativa, ética e democrática.

A situação provocada pela pandemia do COVID-19 evidencia que agora, mais que nunca, é preciso pensar que tipo de cidade e de cidadãos queremos. A resposta a essa questão passa, a nosso juízo, pela necessidade de implementar de forma planejada, vários dos modelos de cidade debatidos neste artigo.

À medida que as cidades aceleram a revisão de sua estratégia de desenvolvimento com foco em ferramentas e tecnologias digitais para responder à pandemia COVID-19, o Programa UNESCO Global MIL Cities (UNESCO, 2020a) oferece oportunidade para as cidades darem passos ousados nessa direção enquanto avançam, simultaneamente, na inclusão, segurança, resiliência, interculturalidade e sustentabilidade em sua vida cotidiana.

O modelo de cidade sugerido, o de Cidade MIL. estabelece sinergias, ou mesmo inclui, muitos elementos dos modelos antecessores. Ao projetar as cidades MIL devemos nos concentrar em uma das principais variáveis: o fato de as cidades físicas estarem se fundindo com as cidades virtuais. O enfoque MIL defende a presença online de maneira crítica, ou seja, a vida online é considerada fundamental para sua eficácia, seja sob a perspectiva de inovação social, seja sob a perspectiva da defesa da cidadania e do combate à infodemia e à desinfodemia. Isto é, propõe desenvolver estratégias utilizando novas tecnologias para combater as fake news, as deepfakes etc. Não obstante, a aprendizagem de MIL também deve ser inserida de forma criativa e participativa nos espaços físicos da cidade e em todas as etapas - entradas, processos e saídas - que garantem a vida na cidade.

\begin{tabular}{lllllll}
\hline Hygeia & Uberlândia - MG & v. 18 & 2022 & p. 1-13 & Página 11
\end{tabular}


A implementação da rede das Cidades MIL envolve inovação nos processos de comunicação, cultura e ética das comunidades. No contexto da responsabilidade social corporativa, pequenas e grandes empresas, sejam privadas ou públicas, têm a obrigação moral de promover o enfoque MIL nas cidades. A esperança também é que as pequenas e grandes empresas participem das Cidades MIL no contexto de seu alcance comunitário e de suas estratégias sociais corporativas.

Futuramente, o avanço e aprofundamento de pesquisas possibilitarão uma análise cuidadosa do modo pelo qual se manifestam nas diferentes culturas os diversos tipos de cidadãos descritos neste artigo.

\section{REFERÊNCIAS}

100 Resilient Cities. Resilient Cities, Resilient Lives Learning from the 100RC Network. Rotterdam, 2019. Disponível em <http://www.100resilientcities.org/wpcontent/uploads/2019/07/100RC-Report-Capstone-PDF.pdf>. Acesso em 30/Jul de 2019.

ARENDT, H. A condição humana. 13. ed. Rio de Janeiro: Forense Universitária, 2016.

ASOCIACIÓN INTERNACIONAL DE CIUDADES EDUCADORAS. Carta das Cidades Educadoras. Disponível em <http://www.edcities.org/rede-portuguesa/wp-content/uploads/sites/12/2018/09/Cartadas-cidades-educadoras.pdf>. Acesso em: 30 de Jul de 2019.

BARRETO, V. O conceito moderno de cidadania. Rev. Dir Adm., v. 192, n. Abr./ Jun., p. 29-37, 1993.

BATTEN, J. Citizen Centric Cities: The Sustainable Cities Index 2018. Amsterdam: [s.n.]. Disponível em: <https://www.arcadis.com/>. Acesso em: 20 dez. 2020.

CHIBÁS ORTIZ, F, Construyendo la red de ciudades MIL: comunicación, educación y salud desde la perspectiva de la UNESCO. La Habana: Pueblo y Educación, 2021 (no prelo).

CHIBÁS ORTIZ,F. GRIZZLE,A. BORGES, A. RAMOS, F. MAZZETTI,B. SILVA JUNIOR,O. Metrics of MIL Cities, Cultural Barriers and Artificial Intelligence analyzed under UNESCO's view: São Paulo case. In: CHIBÁS ORTIZ, F; YANAZE, M. (ed.). From Smart Cities to MIL Cities: Metrics inspired by the vision of UNESCO. São Paulo: ECA-USP, 2020.

CHING, F. D. K. et al. História global da arquitetura. 3. ed. São Paulo: Martins Fontes/SENAC, 2019.

Código de Hamurabi. Disponível em: <http://www.sohistoria.com.br/biografias/hammurabi/>. Acesso em: 20 dez. 2020.

COSTA, M. J. Cidade de Tebas no Egito. Aracajú: [s.n.]. Disponível em: $<$ https://www.egitoantigo.net/artigos-egito-antigo.html>. Acesso em: 16 dez. 2020.

EDCITIES. Carta das cidades educadoras. Barcelona: [s.n.]. Disponível em: $<$ https://www.edcities.org/>. Acesso em: 20 dez. 2020.

FRAGA, R. A história da cidade de Cuzco. Disponível em: <https://muitocurioso.org/historia-dacidade-de-cuzco/>. Acesso em: 1 ago. 2020.

FUNDAÇÃO GETULIO VARGAS. O que é uma Cidade Inteligente?, 2019, Disponível em <https://fgvprojetos.fgv.br/noticias/o-que-e-uma-cidade-inteligente>. Acesso em: 30 de Jul de 2019.

GUEVARA, A. MAULEN I., MARINHO C., ETEROVIC, R., Sustentabilidade: ODS 11 cidades e comunidades sustentáveis, PUC - Pontifícia Universidade Católica de São Paulo, Programa de $\begin{array}{lll}\text { Pós-Graduação em Administração, } & 2020\end{array}$ https://www.pucsp.br/sites/default/files/download/eventos/bisus/5-cidades-sustentaveis.pdf, . Acesso em: 1 ago. 2020.

GRIZZLE, A. MIL Citizens: informed, committed, empowered. Gothenburg: UNESCO, 2020.

GRIZZLE, A. Discurso pronunciado na inauguração do VII Encontro Internacional Cultura, Comunicação, Marketing e Comunidades. São Paulo: Universidade de São Paulo, 2021 (no prelo).

KOBAYASHI, A. R. K. et al. Cidades inteligentes e sustentáveis: estudo bibliométrico e de informações patentárias. International Journal of Innovation, v. 5, n. 1, p. 77-96, 2017.

$\begin{array}{lllllll}\text { Hygeia } & \text { Uberlândia - MG } & \text { v. } 18 & 2022 & \text { p. 1-13 } & \text { Página } 12\end{array}$


KOREA, Planning. Blockchain City. Connectivity of Smart City - The Smart Bridge and Blockchain City", Marcus Evans Smart Cities Conference. October 26, 2017, Seoul. Disponível em: <http://planningkorea.com/portfolio/blockchain-city/>. Acesso em: 30 de Jul de 2019.

KUHRT, A. The Persian Empire: a Corpus of Sources of the Achaemenid Period. 1st. ed. New York, NY: Routledge, 2009.

LIMA, F. A.; LIMA, S. D. C. Building healthy cities: The instrumentalization of intersectoral public health policies from situational strategic planning. Saúde e Sociedade, v. 29, n. 2, p. 1-12, 2020. https://doi.org/10.1590/s0104-12902020200058

MALACO, J. T. S. Da forma urbana. O casario de Atenas. 2. ed. São Paulo: Alice Foz, 2018.

MAULEN, I.; MARINHO, C.; ETEROVIC, R. Sustentabilidade ODS 11 - Cidades e Comunidades Sustentáveis. Trabalho de Aproveitamento da Disciplina Sustentabilidade 1s 2019, Turma: ADM-NB9, de responsabilidade do Prof. Dr. Arnoldo José de Hoyos Guevara. Programa de Pós-Graduação em Administração e Programa de Pós-Graduação em Economia FEA-USP/PUC-SP, 2019.

MINISTÉRIO DA EDUCAÇÃO E CULTURA. Cidades Educadoras. Disponível em: $<$ http://portal.mec.gov.br/>. Acesso em: 20 set. 2020.

MOUTON, M. et al. Towards 'smart cities' as 'healthy cities': health equity in a digital age. Canadian Journal of Public Health, v. 110, n. 3, p. 331-334, 2019. https://doi.org/10.17269/s41997-019$\underline{00177-5}$

OMS - Organização Mundial da Saúde. Healthy Cities. 2020. Disponível em $<$ https://www.who.int/healthpromotion/healthy-cities/en/>. Acesso em 06/ago/2020

THE GUARDIAN. What makes a city resilient? 2014, Disponível em $<$ https://www.theguardian.com/cities/2014/jan/27/what-makes-a-city-resilient>. Acesso em: 30 de Jul de 2019.

UNESCO. Media and Information Literacy. 2020a , Disponível em: <https://iite.unesco.org/mil/>. Acesso em: 8 ago..

UNESCO, MIL Cities. 2020b, Disponível em: <https://en.unesco.org/milcities $>$., Acesso em: 25 jan.

UNESCO, Seoul Declaration on Media and Information Literacy for Everyone and by Everyone. 2020c, Disponível em: <https://en.unesco.org/news/seoul-declaration-media-and-information-literacyeveryone-and-everyone-0>. Acesso em: $01 \mathrm{dez}$.

UNITED NATIONS. 17 Objetivos do Desenvolvimento Sustentável. 2012, Disponível em: $<$ https://sdgs.un.org/\#goal_section>. Acesso em: 1 ago. 2020.

WATSON, B. What makes a city resilient? Disponível em: $<$ https://www.theguardian.com/cities/2014/jan/27/what-makes-a-city-resilient\#: :text=Resilience reflects a city's ability, Detroit's unemployment as Budapest's floods.>. Acesso em: 1 ago. 2020.

WHO-WORLD HEALTH ORGANIZATION. WHO Coronavirus Disease (COVID-19) Dashboard. Disponivel em: <https://covid19.who.int/?gclid=EAlalQobChMI_pimwrWM7gIVUgSRCh28XwiEAAYASAAEgLcv_D_BwE>. Acesso em: 1 ago. 2020.

WHO-WORLD HEALTH ORGANIZATION, WHO public health research agenda for managing infodemics.2021, https://www.who.int/publications//item/9789240019508 Acesso: 16/07/2020

YIN, R. K. Estudo de Caso: planejamento e métodos. 5. Ed. Porto Alegre: Bookman, 2014. 